\section{CORRECTION}

View Article Online

View Journal I View Issue
Check for updates

Cite this: Nanoscale, 2020, 12, 7995

\section{DOI: $10.1039 / \mathrm{d} 0 \mathrm{nr} 90068 \mathrm{k}$}

rsc.li/nanoscale

\title{
Correction: A robust MnaFeNi-S/graphene oxide nanocomposite as a high-efficiency catalyst for the non-enzymatic electrochemical detection of hydrogen peroxide
}

\author{
Shaktivel Manavalan, (DD a Jaysiva Ganesamurthi, ${ }^{a}$ Shen-Ming Chen, ${ }^{* a}$ \\ Pitchaimani Veerakumar (iD) ${ }^{\mathrm{b}, \mathrm{c}}$ and Keerthi Murugan ${ }^{\mathrm{a}}$
}

Correction for 'A robust MnaFeNi-S/graphene oxide nanocomposite as a high-efficiency catalyst for the non-enzymatic electrochemical detection of hydrogen peroxide' by Shaktivel Manavalan et al., Nanoscale, 2020, 12, 5961-5972.

The authors have noticed that the original article contains an incorrect version of Fig. 6(b). Therefore, a corrected version of Fig. 6 is provided below:
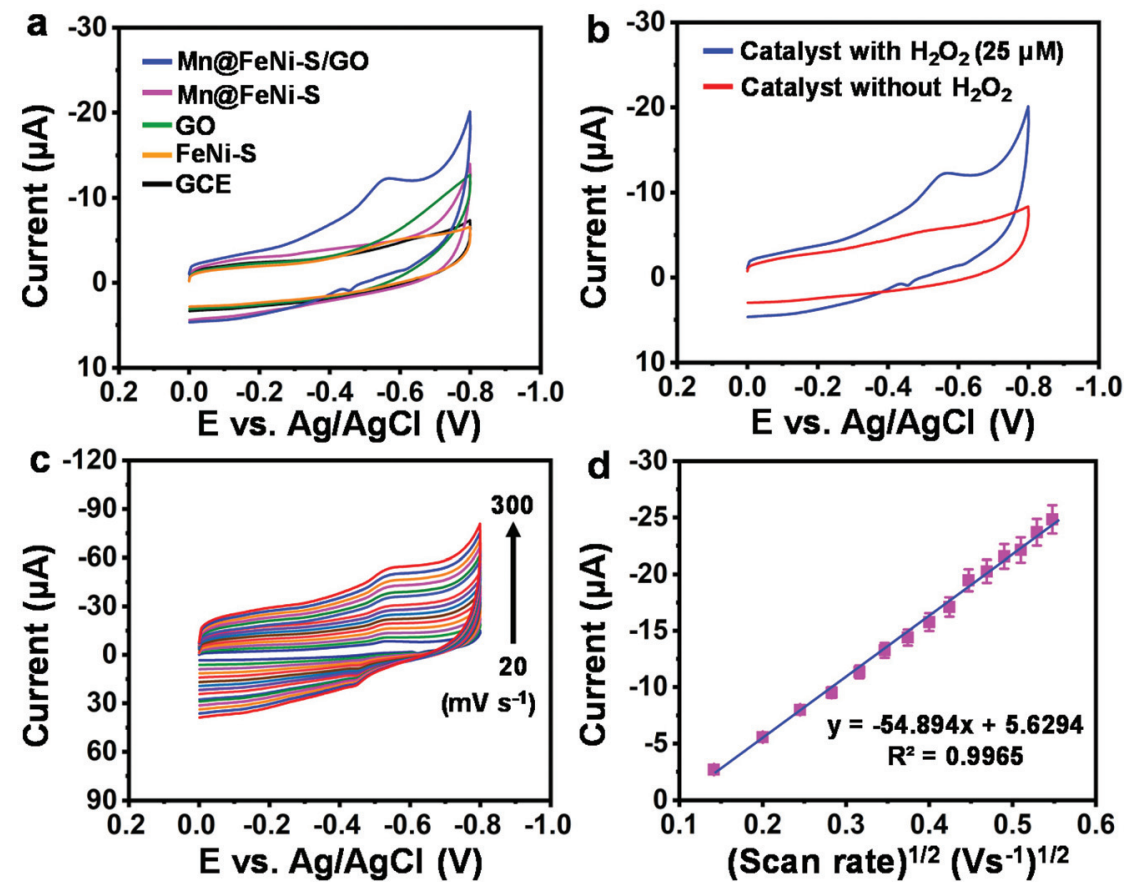

Fig. 6 (a) CV curves of bare GCE, GO, FeNi-S, Mn@FeNi-S, Mn@FeNi-S/GO-modified GCEs containing $25 \mu \mathrm{M}$ of $\mathrm{H}_{2} \mathrm{O}_{2}$ at a scan rate of $50 \mathrm{mV} \mathrm{s}{ }^{-1}$. (b) $\mathrm{CV}$ curves of MnaFeNi-S/GO/GCE with and without addition of $25 \mu \mathrm{M} \mathrm{H} \mathrm{H}_{2}$. (c) CV curves of MnaFeNi-S/GO-modified GCE at different scan rates ranging from $20-300 \mathrm{mV} \mathrm{s}^{-1}$ in $25 \mu \mathrm{M}$ of $\mathrm{H}_{2} \mathrm{O}_{2}$, and (d) the corresponding plot of peak current versus square root of the scan rate. All experiments were conducted in $\mathrm{N}_{2}$-saturated $0.1 \mathrm{M} \mathrm{PB}(\mathrm{pH} 7.0)$.

The Royal Society of Chemistry apologises for these errors and any consequent inconvenience to authors and readers.

\footnotetext{
${ }^{a}$ Department of Chemical Engineering and Biotechnology, National Taipei University of Technology, Taipei 10608, Taiwan, Republic of China.

E-mail: smchen78@ms15.hinet.net; Fax: +886-2-27025238

${ }^{b}$ Department of Chemistry, National Taiwan University, Taipei 10617, Taiwan, Republic of China

${ }^{c}$ Institute of Atomic and Molecular Sciences, Academia Sinica, Taipei 10617, Taiwan, Republic of China
} 